\title{
A Concepção de Estado e a Administração Pública no Brasil no Âmbito do Plano Diretor de Reforma do Estado
}

\section{State conception and public administration in Brazil in the context of State Reform Master Plan}

\author{
José Ricardo Vargas de Faria \\ Professor / Universidade Federal do Paraná \\ Doutorado em Planejamento Urbano e Regional / Universidade Federal do Rio de Janeiro \\ http://lattes.cnpq.br/2623694283407305 \\ orcid.org/0000-0003-2594-3550 \\ jrvfaria@gmail.com \\ José Henrique de Faria \\ Professor Titular Sênior / Universidade Federal do Paraná \\ Doutorado em Administração / Universidade de São Paulo \\ http://lattes.cnpq.br/3738279410631976 \\ orcid.org/0000-0003-3971-7992 \\ jhfaria@gmail.com
}

Resumo: O sentido das transformações pelas quais passou o Estado brasileiro demanda uma análise das forças políticas (e suas alianças), seus projetos e ações, recusando a concepção tecnicista que sugere que se tratou de uma medida puramente administrativa. O presente ensaio teórico tem por objetivo expor as bases para uma análise da chamada Reforma do Estado, destacando as transformações ocorridas no período de 1995 a 1998 , decorrente da implementação do "Plano Diretor de Reforma do Estado". Observa-se que os períodos denominados de "modernização gerencial", segundo o discurso oficial, estão associados à abertura de novos campos e à flexibilização e melhoria das condições para aportes de capitais tanto nacionais quanto internacionais. $O$ procedimento administrativo, portanto, decorre de uma definição política do lugar e do papel do Estado nas relações sociais. Revisando a "perspectiva histórica" sob diferentes bases, desenvolve-se uma análise crítica do ideário que sustentou o Plano Diretor de Reforma do Estado no Brasil. Conclui-se que a Reforma, circunscrita à eficiência de parte de seu aparelho administrativo, não corresponde a uma concepção de inclusão social nos benefícios do desenvolvimento, mas de instrumentalização do aparelho administrativo, segundo uma concepção gerencial, para que o mesmo responda, com mais agilidade e eficiência, às demandas da economia.

Palavras chave: Reforma do Estado, Gerencialismo, Planejamento Econômico

Abstract: The sense of Brazilian State transformations calls for an analysis of the political forces (and their alliances), their projects and actions, refusing the technicist conception that suggests that it was a purely administrative providence. This theoretical essay aims at laying the groundwork for an analysis of the socalled State Reform, highlighting the transformations that occurred in the period from 1995 to 1998, resulting from the implementation of the "Master Plan for State Reform." Argued that the so-called "managerial modernization" periods, according to the official discourse, are associated with the opening of new fields and the flexibilization and improvement of the conditions for national and international capital contributions. The administrative procedure, therefore, stems from a political definition of the place and role of the state in social relations. Reviewing the "historical perspective" under different bases, a critical analysis of the ideology that underpinned the State Reform Master Plan in Brazil was developed. Concluded that the Reform, limited to the efficiency of part of its administrative apparatus, does not correspond to a conception of social inclusion in the benefits of development, but of instrumentalization of the administrative apparatus, according to a managerial conception, so that it responds, more efficiently, to economy demands.

Keywords: State Reform, Managerialism, Economic Planning

\section{INTRODUÇÃO}

No período de 1995 a 1998, durante o primeiro mandato presidencial de Fernando Henrique Cardoso, foi instituído o Ministério de Administração e Reforma do Estado, responsável pela elaboração e implementação do "Plano Diretor de Reforma do Estado" que tinha a finalidade de reformular a administração pública brasileira no sentido de torná-la gerencial. O discurso oficial defendia que esta reforma gerencial se baseava "em conceitos atuais de administração e eficiência, voltada para o controle dos resultados e descentralizada para poder chegar ao cidadão, que, numa sociedade democrática, é quem dá legitimidade às instituições e que, portanto, se torna 'cliente privilegiado' dos serviços prestados pelo Estado", enfatizando a "qualidade e a produtividade do serviço público" (Cardoso, 1995).

Para o Ministério foi indicado Luis Carlos Bresser Pereira, que além de ministro foi o principal teórico, e pode-se dizer também ideólogo, desta reforma. A construção intelectual sobre - e o
Texto completo em português: http://www.apgs.ufv.br Full text in Portuguese: http://www.apgs.ufv.br diagnóstico da - a administração pública brasileira, estabelece um dos suportes para as ações propostas. Este diagnóstico realiza uma periodização da história da administração pública no Brasil considerando a predominância, em determinadas épocas, de certos 'tipos ideais' de Estado. Estes tipos ideais, construídos a partir da formulação weberiana sobre as estruturas de dominação (patriarcal-patrimonial e burocrática), estabelecem certos juízos valorativos sobre as formas de administração como suas características intrínsecas. Contudo, a elaboração de BresserPereira (2006) não corresponde à de Weber (2004), senão em seus aspectos mais gerais, principalmente porque procura definir um melhor ou pior tipo de administração. Para Bresser Pereira (2006) as formas de administração pública patrimonial e burocrática são superadas em diferentes países pela emergência de um novo modelo que denomina de gerencial. No Brasil este modelo se expressa parcialmente em certas iniciativas de reforma administrativa. 
Desta forma, partindo-se de uma perspectiva histórica, verificamos que a administração pública - cujos princípios e características não devem ser confundidos com os da administração das empresas privadas - evoluiu através de três modelos básicos: a administração pública patrimonialista, a burocrática e a gerencial. Estas três formas se sucedem no tempo, sem que, no entanto, qualquer uma delas seja inteiramente abandonada (Brasil, 1995).

Percebe-se, nesta leitura, que os modelos se sucedem como correção das distorções do modelo anterior, em uma perspectiva evolucionista orientada para o entendimento de que o último modelo seria inexoravelmente o melhor, o mais desenvolvido.

No presente momento, uma visão realista da reconstrução do aparelho do Estado em bases gerenciais deve levar em conta a necessidade de equacionar as assimetrias decorrentes da persistência de aspectos patrimonialistas na administração contemporânea, bem como dos excessos formais e anacronismos do modelo burocrático tradicional (Brasil, 1995).

Para desenvolver uma análise crítica do ideário que sustentou o Plano Diretor de Reforma do Estado, torna-se importante indicar o lugar do Estado Capitalista Contemporâneo e, neste mesmo sentido, revisar a "perspectiva histórica" sob diferentes bases, com a finalidade de compreender os processos políticos e econômicos, que considerem - além da reformulação dos aspectos institucionais e administrativos - (i) a emergência de (e o conflito entre) forças e atores econômicos e sociais, (ii) os projetos políticos em disputa e (iii) as concepções dominantes de administração e planejamento. Certamente este projeto não pode ser realizado em algumas poucas páginas e, portanto, o objetivo deste ensaio é propor apenas algumas orientações à sua realização.

Neste sentido, tomar-se-á como referência básica as análises desenvolvidas por Octavio lanni (1977) em "Estado e Planejamento Econômico no Brasil", por Bresser Pereira (2006), em "Reforma do Estado e Administração Pública Gerencial” e por Poulantzas (1977) em "Poder Político e Classes Sociais". O primeiro pelo fato de destacar que as rupturas, no âmbito do Estado, conferem novos conteúdos e reposicionam a relação entre o poder político e o poder econômico, no sentido de tornarem mais agudas as exigências de racionalização. O segundo por apresentar os fundamentos da reforma do Estado por ele mesmo conduzida. O terceiro na medida em que sugere que uma teoria do Estado deve ser capaz de explicar as metamorfoses de seu objeto, considerando que a luta de classes não apenas intervém nas formações sociais como simples fator de variação ou concretização de um tipo ideal de Estado em um ou outro Estado concreto. Neste último caso, o conceito de Estado formulado por Poulantzas serve para posicionar a abordagem teórica e não para formalizar uma conclusão a partir dele. Esta revisão pode tornar possível o questionamento dos objetivos anunciados pela Reforma do Estado no Brasil e a elucidação de outros não anunciados.

\section{As Diferentes Periodizações da Reforma do Estado no Brasil}

A história da administração pública no Brasil apresentada no Plano Diretor de Reforma do Estado encontra-se estruturada a partir de determinados marcos históricos de reforma administrativa e, em função destes, da orientação no sentido da menor ou maior burocratização ou "modernização gerencial". São considerados essencialmente três marcos principais: (i) a criação do Departamento Administrativo do Serviço Público - DASP, em 1938 (criado a partir do Conselho Federal do Serviço Público Civil de 1936); (ii) o Decreto-lei no 200/67 instituído durante o regime militar; (iii) a Constituição Federal de 1988. Cada um destes marcos é tomado, de certa maneira, como momento de inflexão nos rumos do desenvolvimento da administração pública.

O sentido desta inflexão está em uma concepção de administração associada às formas de dominação: racional-legal, tradicional e carismática. Para Weber (2004, p.193) "toda dominação manifesta-se e funciona como administração. Toda administração precisa, de alguma forma, da dominação, pois, para dirigi-la, é mister que certos poderes de mando se encontrem nas mãos de alguém". Desta leitura se desdobram os conceitos de administração burocrática e administração patrimonial, que são utilizados como referência para analisar o sentido das reformas administrativas empreendidas a partir dos três momentos identificados acima. Uma degeneração destes conceitos é comum na literatura administrativa, que os toma como "modelos" de gestão aplicáveis a partir da implementação de determinadas características. Esta ideia aparece também nas referências oficiais sobre a Reforma do Estado (BRASIL, 1995), em Bresser Pereira (2006) e em Torres (2004).

Além destes dois conceitos Bresser Pereira (2006) discute ainda a definição de administração gerencial:

a) descentralização do ponto de vista político, transferindo-se recursos e atribuições para os níveis políticos regionais e locais; b) descentralização administrativa, através da delegação de autoridade aos administradores públicos, transformados em gerentes cada vez mais autônomos; c) organizações com poucos níveis hierárquicos, ao invés de piramidais; d) pressuposto da confiança limitada e não da desconfiança total; e) controle a posteriori, ao invés do controle rígido, passo a passo, dos processos administrativos; f) administração voltada para o atendimento do cidadão, ao invés de auto-referida (Bresser Pereira, 2006, p.243)

Neste caso, o autor não explicita qual forma de dominação estaria associada à esta forma de administração, restringindo apenas a caracterizá-la. A história da administração pública no Brasil é então explicada a partir da tentativa de adoção de tal ou qual modelo.

\section{1ํ período - 1936-1967: a "Burocratização"}

O ponto de partida da periodização decorrente é a afirmação de que as sociedades pré-capitalistas são caracterizadas por uma administração patrimonialista e que, no Brasil, esta seria a forma predominante até a década de 1930. De acordo com Torres (2004, p.143) "da descoberta do Brasil [...] até a Revolução de 1930, o Estado brasileiro pode facilmente ser descrito como a grande instituição garantidora dos privilégios sociais e econômicos de uma elite rural, aristocrática e parasita" caracterizando uma indissociação entre patrimônio público e privado, aspecto central na definição de patrimonialismo. Para Bresser Pereira (2006, p.241) "esse tipo de administração revelar-se-ia incompatível com o capitalismo industrial e as democracias parlamentares que surgiram no século XIX". 
Nesta perspectiva, a reforma administrativa iniciada em 1936, com a posterior criação do DASP em 1938, teve por objetivo instituir uma administração burocrática, sustentada por uma concepção científica da organização do trabalho, ou seja, apoiada nos pressupostas da eficiência e da racionalidade. Esta reforma teria como finalidade a criação das condições para o desenvolvimento do capitalismo, opondo-se à administração patrimonialista, pela "clara separação entre o Estado e o mercado" (Bresser Pereira, 2006, p.241).

$\mathrm{Na}$ análise de lanni (1977) esta idéia é parcialmente afirmada a partir do entendimento de que a "Revolução de 30 [...] cria condições para o desenvolvimento do Estado burguês [...]. Isto significa que o poder público passou a funcionar - mais adequadamente - segundo as exigências e as possibilidades estruturais estabelecidas pelo sistema capitalista vigente no Brasil" (IANNI, 1977, p.13-4). Porém, as rupturas estruturais internas e externas, que promoveram a derrota - mas não a liquidação - do Estado oligárquico, foram realizadas, em parte, por uma forte intervenção e controle do mercado pelo Estado, ao invés de propriamente sua "clara separação". O Estado atua na reformulação das condições de funcionamento (i) do mercado de fatores de produção (manifesta, por exemplo, na consolidação da legislação trabalhista); (ii) das relações internas de produção e (iii) das relações entre economia brasileira e internacional. (lanni, 1977)

Além disso, lanni (1977) destaca que as rupturas, no âmbito do Estado, conferem novos conteúdos e reposicionam a relação entre o poder político e o poder econômico, no sentido de tornarem mais agudas as exigências de racionalização: (i) dos meios e técnicas de organização das informações, (ii) análise de problemas, (iii) tomada de decisões e (iv) controle da execução de políticas econômicofinanceiras. Enfim, embora já houvesse medidas intervencionistas anteriores a 1930, neste período o planejamento passa a ser reconhecido como técnica para aceleração do desenvolvimento econômico. O governo federal assume um papel central (e centralizador) neste planejamento, característica tomada por Bresser Pereira (2006, p.243) como princípio da burocracia clássica.

A análise sobre mudanças na administração pública brasileira após o período Vargas - em Bresser Pereira (2006), Torres (2004) e na análise histórica do constante no Plano Diretor de Reforma do Estado - aponta que "houve poucas ações no sentido de modernizar a administração pública durante o regime democrático de 1945-64" (Torres, 2004, p.150). As poucas experiências "se caracterizaram, em alguns casos, pela ênfase na extinção e criação de órgãos, e, em outros, pela constituição de estruturas paralelas visando alterar a rigidez burocrática" (Brasil, 1995).

Apesar das poucas alterações institucionais/legais que tiveram impacto geral na forma de organização da administração pública federal é necessário observar que ocorreram algumas mudanças nas formas de operação da máquina estatal. Neste período, foram criadas diversas estruturas que operavam de forma parcialmente independente das normas próprias da administração pública (como por exemplo, aquelas relacionadas aos concursos para provimento de cargos públicos, licitações, etc.). Estes organismos eram, em geral, responsáveis por ações estratégicas no campo econômico, como por exemplo, a criação do Conselho Nacional de Desenvolvimento e posterior implementação do Programa de Metas durante o governo JK.

Deste modo, ainda que não tenha havido reformas de amplo espectro, diferentes formas de descentralização e flexibilização (desregulamentação) da gestão ocorreram no período, por meio da criação de diversos organismos de administração indireta responsáveis por programas estratégicos. Pode-se afirmar que o sentido predominante destes processos foi o de conferir mais autonomia para as ações no campo econômico, especialmente no que se refere à mediação dos interesses das diferentes classes e frações de classe em disputa.

\section{2º período - 1967-1988: a "Modernização Gerencial"}

Para Bresser Pereira (2006, p.243-5), em 1967, com a instituição do Decreto-Lei no 200 , ocorreu a primeira tentativa de reforma gerencial na administração publica brasileira, que enfatizava a descentralização administrativa e a autonomia da administração indireta (autarquias, fundações, empresas públicas e sociedades de economia mista), especialmente em relação às atividades de produção de bens e serviços. Em relação a esta autonomia, consolidava-se um processo que, na prática, já se realizava no período anterior pela criação de comissões especiais, conselhos e institutos para tratar de questões estratégicas da administração pública, principalmente na área econômica. Bresser Pereira (2006, p.244) afirma que "através da flexibilização de sua administração [das empresas estatais e fundações] buscava-se uma eficiência maior nas atividades econômicas do Estado, e se fortalecia a aliança política entre a alta tecnoburocracia estatal, civil e militar e a classe empresarial".

Além do Decreto-Lei oㅜ 200, neste período o Governo Militar elabora o Plano Decenal. Ainda que, segundo lanni (1977, 237-8), este plano sequer tenha saído do papel, sua consideração é necessária para melhor compreender as orientações políticas daquele governo. A concepção de planejamento se relaciona com uma perspectiva de livre mercado e conforme afirmou o Presidente Castello Branco (apud lanni, 1977, p.237) a prática do planejamento "é perfeitamente compatível com a descentralização das decisões, na medida desejada, através de sistemas de preços e livre empresa". Sobre este processo lanni (1977) destaca:

Tratava-se de equipar o governo (isto é, o Executivo) para exercer com o máximo de eficácia as suas funções na esfera das relações econômicas. Por isso é que esse mesmo governo (fundamentalmente privatista) tratou de desenvolver ainda mais a tecnoestrutura que deveria regular e dinamizar o funcionamento das forças produtivas e das relações de produção no País. Por isso também, é que a instalação dos Grupos de Coordenação do Plano Decenal começou com um discurso sobre o caráter neutro da técnica de planejamento e sobre a importância da planificação da política econômica governamental (lanni, 1977, p.236)

O fortalecimento da tecnoestrutura, que para Bresser Pereira (2006) recebeu a denominação de "modernização gerencial", esteve intimamente associado à intenção de desenvolver condições: (i) para que as empresas estatais operassem segundo 
a lógica de mercado e (ii) de estimulo ao investimento do setor privado nacional e principalmente o estrangeiro.

No governo Médici, algumas orientações políticas se alteram, porém é possível perceber que os aspectos citados anteriormente são corroborados, conforme as afirmações de Delfim Netto:

É preciso distinguir, no campo econômico, a ação direta do governo e a ação indireta do governo. No caso da ação direta do governo, nada é mais importante que: 1) a preparação de uma burocracia realmente eficiente, responsável e consciente de seu papel; 2) a introdução de métodos gerenciais modernos nas empresas governamentais, inclusive criando-se um nível de administração técnica e financeira estável. [...] No caso da ação indireta do governo, nada me parece mais importante do que: 1) dizer claramente que se decidiu realizar o desenvolvimento com a descentralização do poder econômico, o que significa que o empresário privado será chamado a cumprir suas responsabilidades; [...] 4) deixar funcionar o mercado, estimulando a concorrência e criando as condições para que o sistema de preços reflita, efetivamente, a escassez relativa dos fatores de produção (in lanni, 1977, p.248-9).

Depreende-se daí que "a afirmação da hegemonia da tecnoestrutura", pela autonomização crescente dos níveis gerenciais das empresas estatais e outros órgãos da administração indireta, constitui-se em um dos instrumentos de ação desenvolvidos pelo governo "para criar condições mais propicias à prosperidade da empresa privada, nacional e multinacional" (lanni, 1977, p.250) e promover o crescimento econômico pela reintegração, de forma dependente, do Brasil ao capitalismo mundial (lanni, 1977, p.256).

\section{3ำ período - 1988-1995: o Retrocesso Burocrático e o projeto de Reforma do Estado.}

A argumentação de Bresser Pereira (2006), reproduzida no Plano Diretor de Reforma do Estado, defende que as reformas administrativas empreendidas pela Constituição Federal de 1988 promoveram um retrocesso para a administração pública na medida em que se recrudesceram as práticas burocráticas, estendendo para a administração indireta os mesmos mecanismos de funcionamento da administração direta.

Sem que houvesse maior debate público, o Congresso Constituinte promoveu um surpreendente engessamento do aparelho estatal, ao estender para os serviços do Estado e para as próprias empresas estatais praticamente as mesmas regras burocráticas rígidas adotadas no núcleo estratégico do Estado. A nova Constituição determinou a perda da autonomia do Poder Executivo para tratar da estruturação dos órgãos públicos, instituiu a obrigatoriedade de regime jurídico único para os servidores civis da União, dos Estadosmembros e dos Municípios, e retirou da administração indireta a sua flexibilidade operacional, ao atribuir às fundações e autarquias públicas normas de funcionamento idênticas às que regem a administração direta (Brasil, 1995).

A identificação das causas deste processo aponta para pelo menos dois fatores: (i) por um lado, tratava-se de um discurso de combate ao clientelismo; que se expressava na contratação de pessoal por critérios políticos e nas compras marcadas como processos comuns na administração indireta e (ii) por outro lado, a defesa dos interesses coletivos (corporativos, nos termos de Bresser Pereira) do funcionalismo público; setor bastante organizado durante a Assembléia Constituinte. Como resultado, argumenta-se que ocorreu um aprofundamento da crise do Estado:
No Brasil, embora esteja presente desde os anos 70, a crise do Estado somente se tornará clara a partir da segunda metade dos anos 80. Suas manifestações mais evidentes são a própria crise fiscal e o esgotamento da estratégia de substituição de importações, que se inserem num contexto mais amplo de superação das formas de intervenção econômica e social do Estado. Adicionalmente, o aparelho do Estado concentra e centraliza funções, e se caracteriza pela rigidez dos procedimentos e pelo excesso de normas e regulamentos (Brasil, 1995).

Bresser Pereira (2006) afirma que a crise do Estado de Bem Estar Social (no caso das nações desenvolvidas) e Desenvolvimentista (no caso latino-americano), a partir da década de 80, que se caracterizaria por: (i) uma crise fiscal, pela crescente perda do crédito e de reservas por parte do Estado; (ii) um esgotamento da estratégia estatizante de intervenção do Estado (o Estado do bem-estar social nos países desenvolvidos, a estratégia de substituição de importações no terceiro mundo, e o estatismo nos países comunistas); e (iii) "a superação da forma de administrar o Estado, isto é, a superação da administração pública burocrática" (Brasil 1995). Deste panorama, o Plano Diretor de Reforma do Estado aponta para a adoção de medidas de reformulação do Estado, tanto nos seus aspectos administrativos (ou seja, no aparelho de Estado), quanto no sentido das políticas econômicas e sociais:

Neste sentido, são inadiáveis: (1) o ajustamento fiscal duradouro; (2) reformas econômicas orientadas para o mercado, que, acompanhadas de uma política industrial e tecnológica, garantam a concorrência interna e criem as condições para o enfrentamento da competição internacional; (3) a reforma da previdência social; (4) a inovação dos instrumentos de política social, proporcionando maior abrangência e promovendo melhor qualidade para os serviços sociais; e (5) a reforma do aparelho do Estado, com vistas a aumentar sua "governança", ou seja, sua capacidade de implementar de forma eficiente políticas públicas (Brasil, 1995).

Ao defender a Reforma do Estado, Bresser Pereira (2006) sustenta que a as saídas apontadas para crise do Estado, quais sejam, a reforma fiscal e a redução do Estado (Estado Mínimo), seriam, respectivamente, insuficientes e utópicas. No entanto, ainda que com características diferentes, não é recente a defesa de uma concepção liberal para o Estado brasileiro. Ianni (1977) argumenta que em 1944, um embate entre diferentes perspectivas para condução da economia brasileira no pós-guerra se dá entre, de um lado, os propositores de maior intervenção do Estado através do planejamento, do pensamento técnico-científico e, de outro, os liberais, defendendo a privatização da economia, livre participação do capital estrangeiro e neutralidade do poder público, onde o Estado deveria apenas "estabelecer as regras do jogo" e não interferir nas atividades econômicas. Entre outros fatores, este embate de concepções expressa (e está inserido em) uma disputa de frações de classe no interior da classe dominante.

Neste sentido, para compreender tanto o "retrocesso burocrático", quanto as respostas neoliberais, torna-se necessário desenvolver uma análise que considere a referência a processos gerais (globalização) superando concepção da burocratização, frequentemente citados nos documentos relativos ao Plano Diretor de Reforma do Estado (BRASIL, 1995). Em primeiro lugar, o processo constituinte de 1988 produziu um contexto de enfrentamento sobre a forma da organização e da ação do Estado 
em que se deve considerar entre outros: (i) o fortalecimento das antigas oligarquias durante o período de redemocratização; (ii) o fortalecimento dos sindicatos e movimentos populares durante a década de 1980; (iii) a negação dos elementos associados ao período do regime militar. Já durante a década de 1990 o contexto e a correlação de forças se alteram, sugerindo o questionamento sobre qual o significado destas transformações e de que forma o projeto de Reforma do Estado está implicado neste processo.

\section{O ESTADO CONTEMPORÂNEO}

Os últimos 25 anos se constituem em um privilegiado período para que se estabeleça um corte analítico para o estudo do Estado Contemporâneo nas articulações políticas que favorecem a modernização das relações e do modo de produção e que servem de garantia à sua manutenção. Assim, o processo acelerado de expansão da globalização é o resultado das relações de poder que dão direção política ao Estado e que permitem a definição compartilhada de estratégias deste com os setores produtivos dominantes. É neste contexto que se definem os programas de Reforma do Estado, ou seja, ressaltando o projeto político neoliberal para compreender o processo de reforma do Estado no Brasil e os projetos políticos que o orientaram refletindo os impactos da Reforma considerando o contexto e a trajetória da organização burocrático-administrativa do Estado brasileiro, e seus impactos para a sociedade brasileira e seu embate com o projeto político alternativo a partir do contexto de redemocratização.

Para compreender a proposta de Reforma do Estado de Bresser Pereira, é necessário considerar que as relações sociais de produção constituem o Estado e lhe dão forma e substância, de maneira que este passa a interpretar esses interesses dominantes ao mesmo tempo em que administra os conflitos e as contradições presentes na sociedade. Para afirmar sua função de coordenação, o Estado patrocina a aceleração do processo de expansão da economia capitalista, enquanto estratégia dos setores dominantes do capitalismo contemporâneo, o que desencadeia impactos importantes que afetam as relações sociais de produção, exigindo redefinição ou reforço das relações de poder e definição de novas estratégias políticas, coordenadas pelo Estado. O período em análise é marcado por uma política neoliberal de gestão do Estado como uma resposta à tradição histórica da organização burocráticoadministrativa do Estado brasileiro.

Assim, para desvendar este intricado e complexo fenômeno, é necessária uma análise que contemple três níveis interdependentes de investigação: o jurídico-político, em que deve ser explicitado o papel do Estado em suas relações com a sociedade; o ideológico, que se refere ao patrocínio do sistema de ideias que configura o pensamento dominante neoliberal capaz de dar coerência discursiva ao real; o econômico, em que deve ser destacado o estágio do desenvolvimento marcado pela globalização da economia e que exigia respostas de políticas de governo.

Para melhor compreender porque a globalização acelerou-se de forma tão intensa, é necessário entender o papel que desempenha o Estado na sociedade contemporânea. A questão que precisa ser colocada é: como o Estado Contemporâneo conecta as estruturas econômica, jurídico-política, ideológica e social que atendem os interesses dominantes da sociedade ao mesmo tempo em que articula a garantia institucional do poder político que lhe corresponde? Em outros termos, como o Estado equilibra uma política econômica neoliberal ao mesmo tempo em que incorpora camadas excluídas da sociedade no mercado de trabalho e de consumo?

Para os efeitos desta análise pode-se definir o Estado, a partir do conceito de Poulantzas (1977), como, ao mesmo tempo, fator de coesão da unidade de uma formação social e lugar de condensação das contradições entre os diversos níveis desta formação. O papel do Estado é o de manutenção das condições de produção social e, portanto, de existência e funcionamento da unidade. O Estado não tem, nesta medida, uma função estritamente econômica, estritamente ideológica ou estritamente jurídico-política. É preciso descartar desde já a noção da função particular e única do Estado, na medida em que este possui uma função global de coesão. Além disso, uma teoria do Estado deve ser capaz de explicar as metamorfoses de seu objeto, considerando que a luta social travada em seu interior não intervém apenas nas formações sociais como simples fator de variação ou concretização de um tipo ideal de Estado em um ou outro Estado concreto (Poulantzas, 1981). Para Poulantzas (1981) o Estado, "embora sob formas diferentes, sempre esteve constitutivamente presente nas relações de produção, e assim em sua reprodução" (Poulantzas, 1981, p.20). A implicação dessa assertiva é que o Estado assume políticas de gestão voltadas à realização e viabilização das atividades econômicas e sociais, sendo necessário, assim, reter a relação entre o Estado e sua gestão com a direção geral do processo de produção das condições de desenvolvimento socioeconômico.

Contudo, não se pode incorrer na interpretação de que essa presença do Estado significa a sua simples instrumentalização pelas classes ou grupos dominantes. Em vez de instrumento, o Estado deve ser considerado "como uma relação, mais exatamente como a condensação material de uma relação de forças entre classes e frações de classe, tal como ele expressa, de maneira sempre específica, no seio do Estado" (Poulantzas, 1981, p.147). Em outros termos, uma relação de forças não apenas entre classes antagônicas, mas igualmente entre frações de classes trabalhadoras e frações de classe capitalistas (capital industrial, agrícola, comercial, financeiro).

Quando o Estado é mencionado como organizador político do processo econômico e social, não significa que existe uma primazia do econômico na determinação de sua função. O Estado exerce sua função global de coesão através, igualmente, de seus sistemas jurídico (regras que organizam e disciplinam o mercado capitalista), político (a manutenção de ordem institucional) e ideológico (o papel dos projetos de sociedade). As funções particulares, mencionadas, correspondem sempre a interesses em conflito. As funções econômicas, administrativas, jurídicas e ideológicas do Estado constituem para Poulantzas (1977) funções políticas. 
O Estado comporta, no bojo de sua função de coesão, vários aparelhos que concentram, no nível de suas ações substantivas, as tarefas particulares de interpretação e realização dos interesses sociais. Estes aparelhos, que em conjunto formam a ossatura do Estado, aparecem como forma de concentração das ações de interpretação de interesses nos vários níveis em que estes são efetivados. Significa dizer que não há apenas um aparelho de Estado, mas vários. De fato, existe correspondência entre níveis estruturais e aparelhos de Estado, de forma que podem ser identificados aparelhos econômicos, jurídicos, políticos, repressivos e ideológicos, divisão esta que decorre da função de coesão do Estado. A identificação do Estado como, diretamente, aparelho de Estado, atribui a este um papel de interpretação de interesses segundo uma função particular e única daquele. Nesta ótica, o Estado apareceria ou como instrumento de poder ou como o próprio poder: tanto a visão instrumentalista como a essencialista do Estado possuem complicações não só teóricas, mas práticas, difíceis de superar diante das evidências empíricas. A interpretação dos interesses da classe resulta em ações que fluem, através dos diversos aparelhos, às inúmeras agências ou repartições (quadro administrativo) espalhados pelo território sob a jurisdição de um determinado Estado. Tais agências e repartições são uma espécie de extensão ou posto avançado dos aparelhos.

Formalmente, o núcleo do aparato estatal, de acordo com Jessop (1982, p.341), "compreende distintos grupos de instituições e organizações cuja função social aceita é definir e fazer cumprir decisões coletivas dos membros da sociedade em nome do interesse comum e da vontade geral". A questão que precisa ser entendida é que se o Estado, ele mesmo, é o lugar privilegiado no qual as decisões coletivas podem ser realizadas, ele é também o lugar onde a bem-sucedida organização do bloco hegemônico do capital pode definir e realizar seus interesses específicos, a despeito dos interesses de outros grupos ou classes sociais. Isto significa que as decisões estratégicas não são submetidas aos membros da sociedade em nome da vontade geral, pois que se trata de decisões estratégicas privadas.

Este conceito indica que o Estado é uma propriedade social apenas aparentemente. Como observa Jessop (1982 p.342), "o interesse comum é sempre assimétrico, marginalizando e definindo certos interesses ao mesmo tempo em que privilegiam outros. Não é o interesse geral que contém todos os interesses particulares [...]", mas, convém acrescentar, são os interesses particulares que pretendem expressar os interesses gerais. O propósito do Estado Contemporâneo é representar os interesses dominantes e simultaneamente assegurar a coesão social. Neste sentido, 0 Estado reproduz as conexões econômicas e sociais que caracterizam o modo de produção dominante e o faz através de ações e projetos que compreendem desde a formulação das normas jurídicas até investimentos na infraestrutura urbana e social, mecanismos de financiamento da iniciativa privada, acordos internacionais, política financeira e orçamentária, disseminação de compostos ideológicos e política econômica em seu sentido mais amplo. A Reforma do Estado, assim, compreende a reforma de suas atribuições políticas e administrativas. É neste sentido que se pode compreender a proposta de reforma de Bresser Pereira.

A reforma do aparelho de Estado, no entanto, não é de menor importância na compreensão das relações de poder. A própria presença ou ausência de determinadas representações nos diferentes aparelhos de estado informam sobre os interesses ou papéis que tais aparelhos podem cumprir na reprodução social e na reafirmação ou confrontação de certos interesses particulares de classes ou frações de classe. As transformações de ordem administrativa, assim, também possuem relação com as transformações na esfera econômica. A terceirização de serviços, a privatização de empresas públicas, as concessões de infraestrutura, por exemplo, apoiam-se na retórica da eficiência do mercado para alocação de recursos escassos, que se impõem em função do interesse político dominante. A mercantilização de segmentos de atividade econômica à necessidade de continua expansão da base econômica como requisito da superação das crises no contexto do capitalismo. São, portanto, esse os interesses que presidem tais processos.

O Estado, em relação à sociedade, tendo em vista seu papel de articulação, deve assumir uma face pública legível e legitimada, decorrente das formas como se organizam as forças políticas (Ansart, 1978). Neste sentido, o Estado Contemporâneo vem sendo identificado de acordo com esta nova face que assumiu após o que se denominou o fracasso do chamado Estado de Bem-Estar Social, do liberalismo e do keynesianismo, medido pelas dificuldades destes modelos de Estado em gerar crescimento e desenvolvimento econômico, ou seja, pelo esgotamento dos paradigmas. Esta nova face tem sido identificada como de natureza neoliberal, ou seja, um processo que ainda não se definiu precisamente como um modelo, e que retoma a concepção dos liberais acerca da intervenção do Estado na economia, ampliando, entretanto, seu escopo na medida em que procura extrair da experiência keynesiana, especialmente da socialdemocracia e do Estado de Bem-Estar social, algumas vantagens econômicas e sociais relevantes. Para Ramalho Neto (2004), o neoliberalismo é um processo em movimento e não uma essência; é antes um adjetivo do que um substantivo, razão pela qual se pode falar em um processo neoliberal.

Neste sentido, o Estado tem se tornado refém do mercado. Para Ramalho Neto (2004) "uma coisa é a competição regulada pela lei. Outra coisa é a lei regulada pela competição". Nas práticas de classe do Estado Contemporâneo, "a cidadania migra do indivíduo para o consumidor, pois o neoliberalismo não tem relação com os indivíduos, mas com os agentes econômicos". O neoliberalismo, continua Ramalho Neto (2004), "é a dissolução do direito. Quando o Estado transfere suas funções sociais, como a previdência, a saúde, a educação e a infraestrutura ao setor privado, o direito é dissolvido. Assim, o Estado deixa de ser o ente político soberano para transferir esta soberania para o mercado".

Para Rosa Luxemburgo (1970, p. 9), a reforma não é o fim último, mas um método que visa melhorar a situação social e gradualmente estabelecer um controle progressivo sobre o sistema 
econômico sem alterá-lo. Desta maneira, o aperfeiçoamento do Estado serviria para apaziguar os conflitos e atenuar as contradições, conservando, contudo, sua forma estrutural, de sorte que os fatores de adaptação sejam capazes de evitar o desmoronamento de tal sistema, assegurando sua permanência em outros termos. Uma Reforma do Estado, nesta acepção, serviria para o desenvolvimento do sistema econômico e social provendo mecanismos de correção de suas contradições e instrumentalizando esse sistema segundo uma prática institucional.

Tomando esta concepção de Reforma do Estado ou reforma social, mesmo que seja como fim último ou teleológico, evidenciase que o projeto enunciado por Bresser Pereira trata não da transformação do Estado ele mesmo e de uma nova estrutura, mas de uma resposta às exigências decorrentes de sua função de coordenação. A reforma proposta deveria atender à demanda social de articulação, que exigia uma reorganização do aparelho administrativo, historicamente contido nas amarras burocráticas. A necessidade de uma reforma administrativa, que conferisse maior agilidade às ações políticas do Estado, foi uma resposta à necessidade de efetivação de uma política econômica e social.

Sem embargo, a Reforma do Estado brasileira teve, como objetivo, tornar o aparelho administrativo mais eficiente, em uma perspectiva gerencial, para dar conta de sua função de coordenação. Não se tratava nem de resolver as contradições do sistema de capital em sua materialidade, nem de orientar o desenvolvimento das forças produtivas capitalistas, tampouco de apaziguar os conflitos sociais. A reforma que Bresser defende pode ser considerada, tanto como uma reorganização funcional de determinados setores do aparelho administrativo público, como uma alavanca para a desoneração deste aparelho através de uma incursão no plano das "organizações sociais", as quais deveriam assumir atividades próprias da administração pública, de acordo com novas formas jurídicas e por parcerias público-privadas. Tratava-se de uma reforma neoliberal contra o estamento burocrático e contra o aparelhamento da estrutura administrativa.

Ainda que Bresser Pereira (2006, p.30-3) argumente pela mera ocorrência simultânea entre Reforma do Estado e Neoliberalismo, o que levaria a uma suposta confusão por parte dos analistas, rigorosamente, a proposta de Reforma do Estado, insere-se na lógica neoliberal de desoneração do aparelho público do Estado, transferindo ao setor privado a condução de algumas atividades sobre as quais haveria um controle popular se executadas no âmbito do poder público. O resultado da proposta de Bresser Pereira não foi exatamente uma reforma, mesmo que administrativa e gerencial, pois as ações implementadas não resultaram em alterações substantivas para 0 aprimoramento da ordem socioeconômica e jurídico-política do Estado, mas em arranjos específicos em determinados setores de atividade no interior de uma relação de forças. As intervenções foram pontuais para, como já expresso, garantir ao Estado sua função de coordenação econômica e social segundo o ideário neoliberal.

O surgimento de uma nova sociedade informacional em que a produção do conhecimento e sua disseminação, aliadas às tecnologia físicas de informação, ganham destaque, favorecem a construção e o desenvolvimento de um modelo de Estado governado de acordo com os pressupostos neoliberais, que assentam suas bases políticas nas novas economias e estruturas organizacionais, representados pela sociedade em rede, através de cooperações, fusões, aquisições e alianças estratégicas, capazes de conferir vantagens políticas e também econômicas, marcadas pela competitividade no mercado internacional. A questão posta por Bresser Pereira, como exposto, era responder de forma ágil às novas exigências de uma economia globalizada.

Este modelo, contudo, tende a acentuar as diferenças sociais tornando cada vez mais presente os extremos de riqueza e pobreza. Frente a esta realidade, algumas correntes políticas buscaram um novo caminho de prática política, defendendo a chamada "terceira via", que visava adaptar a socialdemocracia a este novo contexto, superando o neoliberalismo, enquanto outras ainda defendem a possibilidade da convivência entre as diferentes demandas de classes com a preservação da lógica do mercado, mesmo com a acentuação dos hiatos sociais existentes, numa política contextualizada frente ao recente processo de globalização.

\section{POR UMA Conclusão}

A definição das prioridades de investimento, das diretrizes gerais de desenvolvimento, de ocupação territorial, entre outras, está vinculada: (i) por um lado, às condicionantes sociais, políticas e econômicas que participam na estruturação da sociedade e do Estado e delimitam a ação governamental e; (ii) por outro lado, às ações e disputas entre classes, frações de classe, grupos e movimentos sociais que podem resultar na própria reconfiguração das condicionantes apontadas. Deste modo, compreender a forma de estruturação do Estado, em seus diversos aspectos, inclusive administrativos, vai além de proposições gerais como a garantia dos contratos e da propriedade privada. O sentido das transformações pelas quais passa o Estado brasileiro exige a análise das forças políticas (e suas alianças), seus projetos e ações.

A Reforma do Estado, circunscrita à eficiência de parte de seu aparelho administrativo, não corresponde a uma concepção de inclusão social nos benefícios do desenvolvimento socioeconômico. Trata-se, antes, de instrumentalizar o aparelho administrativo, segundo uma concepção gerencial, para que o mesmo responda, com mais agilidade e eficiência, às demandas da economia. As reformas propostas por Bresser Pereira, de fato, procuraram dotar o Estado de instrumentos gerenciais de política econômica mais ágeis, superando a estrutura administrativa burocrática que historicamente caracterizava o aparelho governamental, de maneira a, cumprindo seu papel de coordenação e articulação, fazer do Estado, como bem argumenta Poulantzas (1977), um fator coesão dos interesses dominantes. Com isso, as políticas patrocinadas pelo Estado puderam conferir maior competitividade aos empreendimentos produtivos diante do processo de globalização.

Ao mesmo tempo, acompanhado do Plano Diretor de Reforma do Estado, uma série de outros processos ocorridos 
concomitantemente, auxiliam a explicar as alterações pelas quais passou o Estado brasileiro no período final do século passado e início deste. As novas formas de relação entre o Estado e organizações privadas do "Terceiro Setor" (Organizações filantrópicas, Organizações sem fins lucrativos, ONG's, Organizações privadas de interesse público), por exemplo, além da criação de figuras jurídicas novas no âmbito do Estado, como por exemplo as organizações sociais e agências autônomas, denotam um processo de privatização das próprias políticas sociais, ainda que, paradoxalmente, Bresser Pereira (2006) denomine este processo de "publicização". Ainda no campo econômico, também se verificou um intenso processo de privatização das empresas estatais e a constituição de agências reguladoras que orientam para um novo sentido da ação do Estado neste campo. Assim, a Reforma do Estado, empreendida pelo governo federal durante a primeira gestão de Fernando Henrique Cardoso, que se anunciou como corretivo das reformas neoliberais, delas não se distanciou.

Porém, não é suficiente afirmar que as reformas foram orientadas exclusivamente para criação de melhores condições de desenvolvimento do capitalismo local em suas diferentes formas. Observa-se que os períodos denominados de "modernização gerencial", segundo o discurso oficial do Plano Diretor de Reforma do Estado, estão associados à abertura de novos campos e à flexibilização e melhoria das condições para aportes de capitais tanto nacionais quanto internacionais.

Na perspectiva de lanni (1977, p.5-6) as "políticas econômicas governamentais podem revelar o modo pelo qual se organizavam e mudavam as relações entre classes sociais; [ou] dentro de uma classe [exprimindo, ainda] o modo pelo qual as relações e estruturas econômicas e políticas se organizam, antagonizam e modificam".

O presente ensaio teórico procurou formular as bases para uma análise da chamada Reforma do Estado, incorporando também o estudo das transformações ocorridas no aparelho de Estado, mais especificamente, na sua forma de organização administrativa e da tecnoestrutura que, conforme lanni (1977), seria também uma expressão destes processos. Desta forma, procurou-se evitar as opções tradicionalmente observadas na literatura administrativa que percebem as mudanças nas formas de administração pública como simples incorporações de técnicas das empresas privadas (como imitação) ou mesmo inovações surgidas da necessidade de resolver problemas de operação. A realidade oferece elementos bem mais complexos e contraditórios, no sentido de exigir uma análise das forças políticas e dos processos que entremearam a Reforma do Estado, o que demanda o desenvolvimento de uma pesquisa empiricamente referenciada.

\section{BIBLIOGRAFIA}

Ansart, P. (1978). Ideologias, conflitos e poder. Rio de Janeiro: Zahar. BRASIL. (1995). Plano Diretor da Reforma do Estado. Brasília.

Bresser Pereira, L. Carlos. (2006) Reforma do Estado e Administração Pública Gerencial. $7^{\mathfrak{a} e}$ ed. Rio de Janeiro: FGV.

Cardoso, Fernando Henrique. (1995) Apresentação. In: BRASIL. Plano Diretor da Reforma do Estado. Brasília.

Ianni, Octavio. (1977) Estado e Planejamento Econômico no Brasil (19301970). Rio de Janeiro: Civilização Brasileira.

Jessop, B. (1982) The capitalist state: Marxist theories and methods. Oxford: M. Robertson.

Luxemburgo, Rosa. (1970) Reforma ou Revolução. Lisboa : Estampa.

Poulantzas, N. (1977) Poder político e classes sociais. São Paulo: M. Fontes. Poulantzas, N. (1981) O Estado, O Poder, O Socialismo. 4aㅡ ed. Rio de Janeiro: Graal.

Ramalho Neto, A. M. (2004) Estado e pobreza: entre o social e o assistencial. In: I CONGRESSO BRASILEIRO DE DIREITO POLÍTICO, 1., 2004, Curitiba: IBDP. (Painel n.10).

Torres, Marcelo Douglas de Figueiredo. (2004) Estado, democracia e administração pública no Brasil. Rio de Janeiro: FGV.

Weber, Max. (2004) Economia e Sociedade. V.1. 4ªed. São Paulo: UNB / Imprensa Oficial. 